\title{
Control and emulation of small wind turbines using torque estimators
}

\author{
Juan M. Guerrero*, Carlos Lumbreras ${ }^{\dagger}$, David Reigosa, Pablo Garcia, Fernando Briz \\ Email: *guerrero@uniovi.es
}

\begin{abstract}
Soft-stall control of small wind turbines is a method to protect the generation system and/or load from excessive wind speeds and wind gusts without discontinuing power generation. Soft-stall can be activated due to either an excess of the power and/or torque/current. This paper proposes a method to improve the existing soft-stall methods for over torque/current protection using a turbine torque estimator. In addition, this paper also proposes two methods to emulate the wind turbine inertia without communications between the load drive (wind turbine emulator) and the generation system controller. This will allow the evaluation of the proposed methods in working conditions.
\end{abstract}

\section{INTRODUCTION}

The increasing electrical energy demand has boosted the interest in renewable energy sources due to economical and sustainability reasons. The development of the energy conversion technologies has also brought opportunities to small scale consumers to produce electricity to cover all or part of their electrical energy needs, normally using photovoltaic panels and small wind turbines, the second being considered advantageous in terms of power density and cost.

To become attractive to private consumers, small wind turbines should be able to operate unattended under a broad range of weather conditions. Self protection of the wind turbine under high wind speed situations is mandatory in this case. When the power produced by the turbine exceeds load or generator rated powers, the turbine must be operated at a reduced efficiency to avoid damage either to the load or to the generator. A variety of methods to decrease the turbine efficiency under high wind speed have been proposed, including pitch, furling and stall control, mechanical brakes and electric brakes [1], pitch and furling being only possible in variable pitch wind turbines. The electric brake is the preferred option for small wind turbines due to its simplicity and low cost. However, activation of the electrical brake produces a high torsional torque in the turbine shaft and large currents in the generator windings what stresses the system significantly. A negative temperature coefficient resistor (NTC) crowbar has been proposed to mitigate those problems [1], [2]. Nevertheless, the activation of the crowbar discontinue the power generation. Furthermore, the occurrence of successive start and stop cycles can stress or even damage the turbine.

To avoid the electric brake activation various soft-stall methods have been proposed [3]-[6]. These methods limit the power produced by the wind turbine by reducing its efficiency. To achieve this goal, the turbine speed is decreased, and therefore operates with a non-optimal tip speed ratio (TSR).

In [7] a soft-stall method using the generator and/or power converter current limit (or alternatively by generator torque limit) instead of the rated power of the connected load was proposed for generator protection. This method also allows automatic reconnection of the system if the crowbar has been activated. However, this strategy suffers from some limitations, including large transient currents when a high wind speed condition is detected, and reduced accuracy detecting high wind speed conditions, which can unnecessarily limit the power supplied by the generator.

This paper proposes a method for the soft-stall control of small wind turbines. It is assumed that the turbine is connected to the grid. Consequently, the limit for the maximum power that can be generated come exclusively from the wind turbine power limit, no further restriction being imposed by the load.

The method proposed in this paper overcomes the limitations of the method proposed in [7], a turbine torque estimator is used for this purpose. The estimator allows fast and accurate detection of high wind speed conditions, decreasing the required braking torque/current compared to [7]. Furthermore, precise information on the produced torque allows to operate the generator at its torque limit, therefore increasing the power generation. An additional advantage is a simpler implementation.

As a second contribution, the paper proposes two methods to emulate the turbine inertia. The emulation of the mechanical inertia using electric drives is needed in test benches used for the development of control methods for wind turbines. Several concepts have been reported for this purpose. Analog electronic feedback techniques were early employed [8]. An open-loop inertia emulator based on the synchronized speed control of the load drive and the generator was proposed in [9]. Some of these methods require direct or indirect measurement of the generator torque [10]-[12]. Specially interesting are methods which do not require to measure/estimate the torque, as in this case it is not needed to share information between the load drive and the wind energy controller. The possibility to estimate torque from acceleration was presented in [13]. Disadvantages of this proposal are its sensitivity to system noise and instability problems, which are intrinsic to the discrete-time acceleration calculation [14]. A state-space based turbine torque estimator overcoming that problem was proposed in [15]. However, the dynamic performance of that solution have not been investigated and the estimator gain tuning is not described.

The inertia emulation methods proposed in this paper estimate the turbine torque by comparing the actual machine rotor speed with an estimate provided by a model. Therefore, they do not require torque sensors nor communications between the load drive and the wind turbine controller. The gain tuning procedure and dynamic performance of both methods are in-depth analyzed. The propose methods can be easily implemented in commercial torque-controlled drives.

This paper is a revised and extended version of conference paper [16]. The present version further analyzes the performance and development of the proposed methods providing 


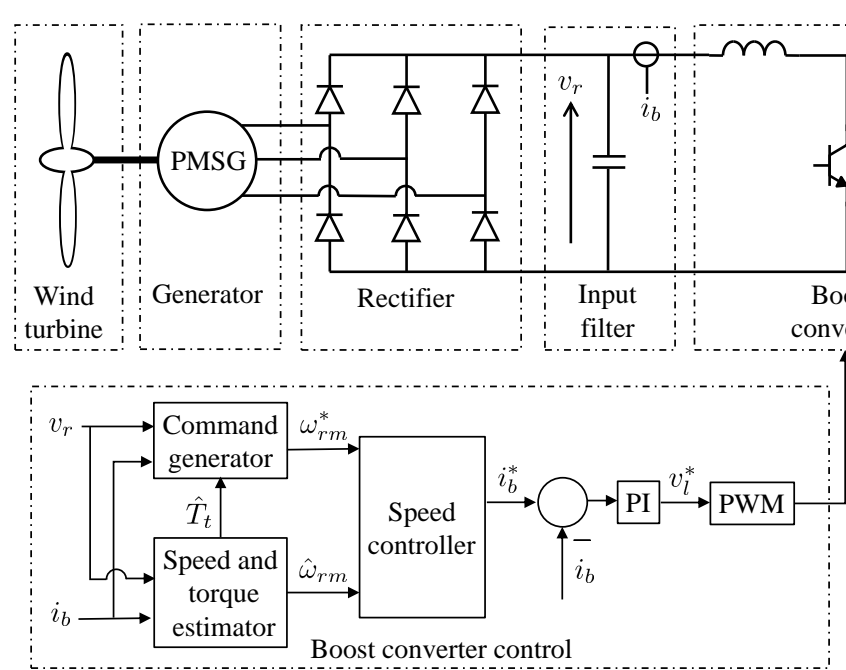

(b)
TABLE I: Turbine parameters

\begin{tabular}{|l|c|}
\hline Rated power output & $1.2 \mathrm{~kW}$ \\
\hline Rated wind speed & $12 \mathrm{~m} / \mathrm{s}$ \\
\hline Rated rotor speed & $600 \mathrm{rpm}$ \\
\hline Turbine radius, $R$ & $0.875 \mathrm{~m}$ \\
\hline Turbine inertia constant, $J_{t}$ & $0.74 \mathrm{~kg} \cdot \mathrm{m}^{2}$ \\
\hline Optimal TSR, $\lambda_{\max }$ & 4.6 \\
\hline Optimal power coefficient, $c_{p_{\_} \max }$ & 0.47 \\
\hline
\end{tabular}

additional insight for both the wind turbine control method and the inertia emulators.

\section{SYSTEM DESCRIPTION}

The wind energy generation system described in this paper can be seen in Fig. 1(a). A fixed-pitch wind turbine is directly coupled to a 12-pole permanent magnet synchronous generator (PMSG). The parameters of the wind turbine used in this study can be found in Table I. The PMSG parameters can be seen in Table II. The machine terminals are connected to a diode rectifier. A boost converter increases the voltage to the required level to inject current to a single-phase grid through an H-bridge inverter and a line filter.

This topology is broadly used in low-cost turbines due to the reduced cost of the diode rectifier compared to a full bridge controlled rectifier. Further cost reduction is achieved due to the reduced number of sensors compared to the backto-back configuration, two voltage sensors and one current sensors being saved. Sensors required by this solution are shown in Fig. 1 and include three voltage sensors (resistor dividers) to measure the rectified voltage, $v_{r}$, the DC-link voltage, $v_{d c}$, and the grid voltage, $v_{g}$; and two current sensors (Hall effect) acquiring the boost current, $i_{b}$ and the current injected to the grid, $i_{g}$. The main drawback of the diode rectifier solution compared to the back-to-back topology is the reduced efficiency.

Control system is shown in Fig. 1(b)-(c), it splits into two subsystems: boost converter control and H-bridge inverter control.
TABLE II: Generator parameters

\begin{tabular}{|c|c|}
\hline Rated power & $2.1 \mathrm{~kW}$ \\
\hline Rated speed & $600 \mathrm{rpm}$ \\
\hline Rated current & $3.7 \mathrm{~A}$ \\
\hline Stator resistance & $6.03 \Omega$ \\
\hline Inductance, $L_{d}=L_{q}$ & $63 \mathrm{mH}$ \\
\hline Back-emf constant, $k_{e}$ & $1.188 \mathrm{~V}_{\text {peak }} / \mathrm{rpm}$ \\
\hline Pole number, $p$ & 12 \\
\hline Inertia constant, $J_{g}$ & $.00581 \mathrm{~kg} \mathrm{~m}^{2}$ \\
\hline
\end{tabular}

The boost converter feeds the DC-link and uses a proportional-integral (PI) controller to regulate the boost current. The output of the controller is the voltage command for the boost inductor, $v_{l}^{*}$, from which the duty cycle of the power switch is obtained. The current command is provided by the wind turbine speed controller, using the speed command and the speed estimate provided by the blocks seen in Fig. 1(b), this discussed in detail in section IV.

The H-bridge controls the DC-link voltage using a well known cascaded structure, its block diagram is shown in Fig. 1(c). The inner loop controls the current injected to the grid, $i_{g}$, a proportional-resonant (PR) controller is used for this purpose. The outer loop controls the DC-link voltage using a PI controller. A notch filter tuned to $100 \mathrm{~Hz}$ is added to filter-off any power oscillations coming from the singlephase AC system. $i_{g_{-} R M S}^{*}$ is the rms value of the grid current command, which is converted into an instantaneous grid current command $i_{g}^{*}$. Synchronization with the grid voltage is required, a phase-locked loop (PLL) was used for this purpose, see "Grid sync." block in Fig. 1(c). $v_{l f}^{*}$ is the voltage command, which is converted by the control in the duty value required by the pulse width modulation (PWM).

\section{OPERATIONAL LIMITS}

This section describes the operation boundaries of the generation system obtained from the turbine characteristic curves. The curves have been derived from experimental data 


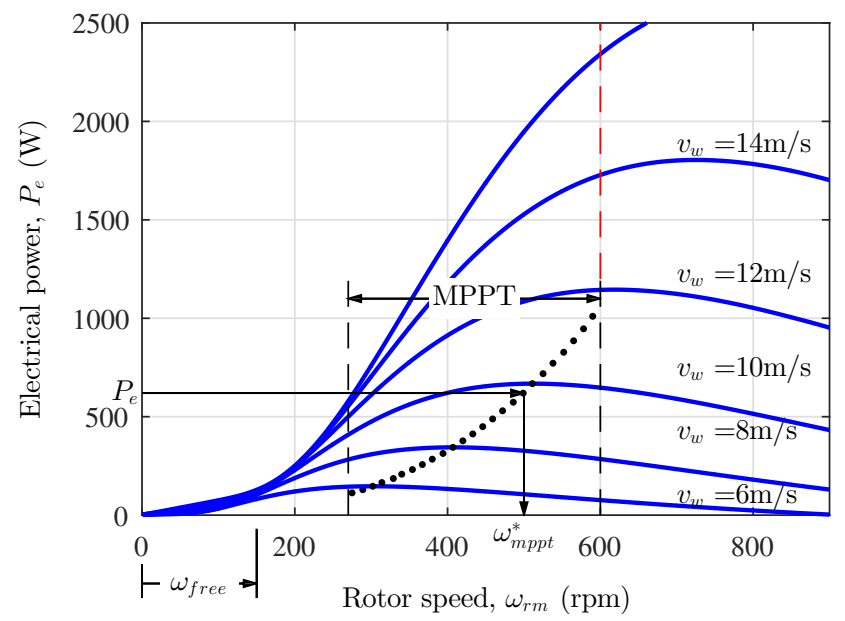

Fig. 2: Electrical power versus rotor speed for different wind speeds. The dotted line indicates the MPPT trajectory. Cut-in speed is $270 \mathrm{rpm}$, cut-off speed is $600 \mathrm{rpm}$.

provided by the turbine manufacturer considering steady-state conditions.

\section{A. Maximum Power Point Tracking (MPPT)}

The electrical power that can be generated in terms of the rotor speed in steady-state operation for different wind speeds is shown in Fig. 2. The MPPT trajectory in Fig. 2 is approximated using a nine-point interpolation function (1), which will be used later by the turbine control.

$$
\omega_{m p p t}^{\prime *}=\hat{f}_{1}\left(P_{e}\right)
$$

where * stand for commanded values and ^ for approximate functions or estimated values.

The minimum speed at which the speed controller is enabled is speed $\omega_{\text {free }}$ (see Fig. 2). This lower speed limit is required to allow the rectifier output voltage to reach the minimum value to operate the boost converter. Below this rotor speed, the wind turbine will move freely as dictated by the wind speed. The minimum speed threshold is also required to guarantee the convergence of the rotor speed and turbine torque estimators, this is described in section IV

The generator torque vs. rotor speed is shown in Fig. 3 for different wind speeds. The torque MPPT trajectory is readily derived from Fig. 2. This trajectory is approximated by a five-point interpolation function (2), which is later used for the turbine control.

$$
T_{m p p t}= \begin{cases}0, & \text { if } 0 \leq \omega_{r m}<270 \mathrm{rpm} \\ \hat{f}_{2}\left(\omega_{r m}\right), & \text { if } 270 \leq \omega_{r m} \leq 600 \mathrm{rpm}\end{cases}
$$

\section{B. Operation at high wind speeds}

For the case of small power wind turbines connected to a relatively stiff grid, it can be assumed that all the power produced by the turbine can be absorbed by the grid. In this case, there is no need to limit the turbine output power, only the voltage and current/torque limits of the generator and power converter must be considered. Fig. 4 shows the turbine torque in terms of the rotor speed for three different values of the wind speed in the high wind speed range. To keep

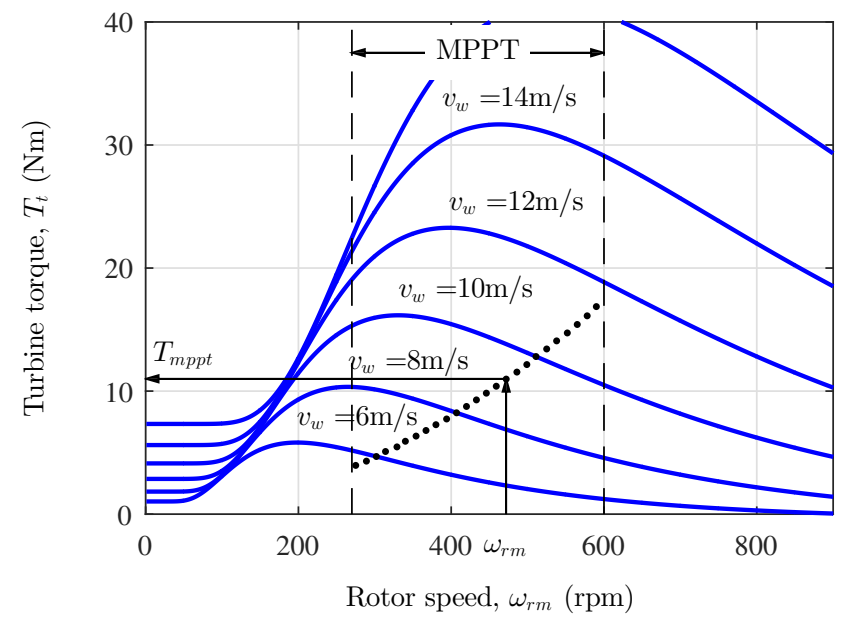

Fig. 3: Turbine torque versus rotor speed for different wind speeds. The dotted line indicates the MPPT trajectory.

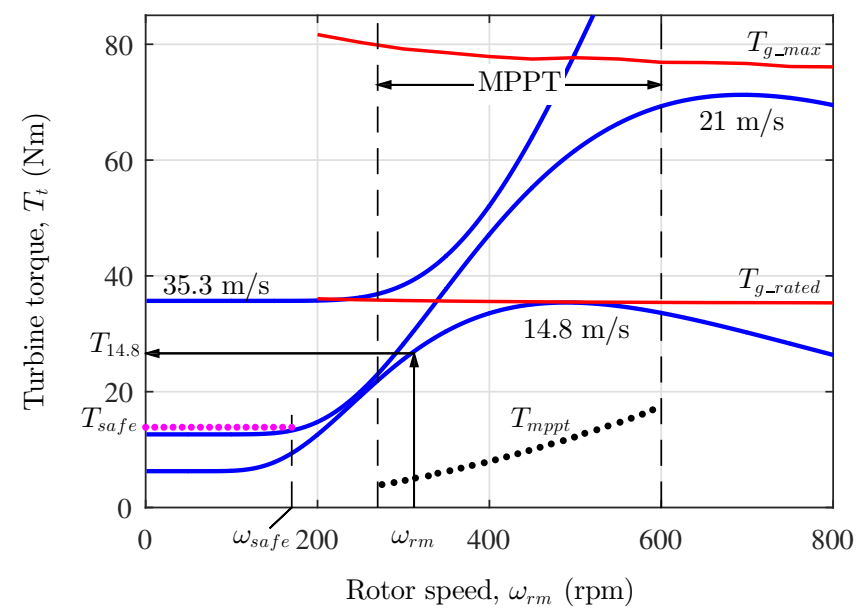

Fig. 4: Turbine torque versus rotor speed for key high wind speeds. $T_{g_{-} \text {rated }}$ indicates the maximum steady state torque. $T_{g_{-} \max }$ indicates the maximum torque.

the turbine under control, the generator should be capable to counteract the turbine torque in all the cases. Rated torque $T_{g_{-} \text {rated }}$ (which occurs when the boost converter operates at its rated current) and maximum torque torque $T_{g \_} \max$ i.e. the torque available to handle transient overloads [17], are shown in the figure. It is noted from Fig. 4 that the maximum torque $T_{g_{-} \max }$ does not only depend on the boost converter current magnitude, but depend also on the rotor speed, due to the operation with a non-unity power factor at high speeds.

It is observed from Fig. 4 that for a wind speed of $14.8 \mathrm{~m} / \mathrm{s}$, the turbine torque matches $T_{g_{-} \text {rated }}$. Therefore, this wind speed will produce the fastest rotor acceleration without surpassing the generator torque limit. The torque profile for this wind speed was stored in a interpolation function (3). This function will be used later to produce the speed command, this is explained in section IV.

$$
T_{14.8}=\hat{f}_{3}\left(\omega_{r m}\right)
$$

It is also observed from Fig. 4 that wind speeds of $21 \mathrm{~m} / \mathrm{s}$ produce a torque close to, but below $T_{g_{-} \max }$, meaning the 


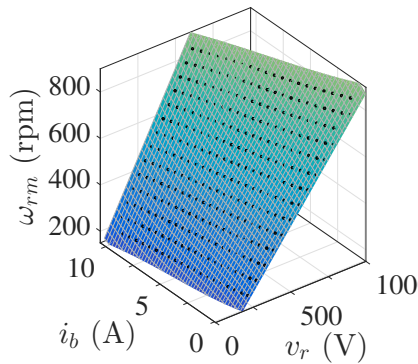

(a)

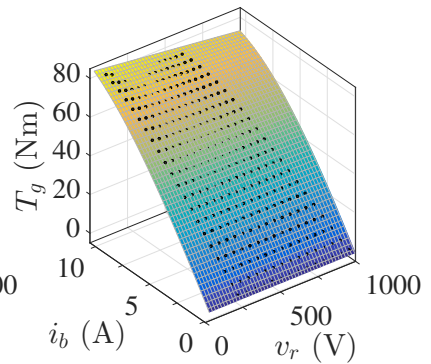

(b)
Fig. 5: a) Measured rotor speed and b) measured generator torque, for different values of the rectifier voltage and boost current

the generator still can counteract the turbine torque for short periods of time and therefore brake it, independently of the rotor speed. At higher wind speeds, the capability of the generator to counteract the wind turbine torque depends on the rotor speed, being feasible at low rotor speeds, but not at high rotor speeds. The maximum wind speed at which the generator can counteract the turbine torque is $35.3 \mathrm{~m} / \mathrm{s}$. For larger wind speeds an external brake systems would be required. In Fig. 4, a safe speed $\omega_{\text {safe }}$ is defined. $\omega_{\text {safe }}$ corresponds to a speed at which the generator can compensate the turbine torque when the wind speed is $35.3 \mathrm{~m} / \mathrm{s}$. The torque produced by the turbine at $\omega_{\text {safe }}$ by a wind speed of $21 \mathrm{~m} / \mathrm{s}$ is termed $T_{\text {safe }}$. These two values will be used for the turbine protection under high wind speeds as will be explained in section IV.

\section{ROTOR SPEED AND TURBINE TORQUE CONTROL}

Depending on the mode of operation, the wind turbine can be controlled either to follow the MPPT trajectory or to produce rated torque. Since neither speed nor torque sensors are available, to implement the proposed strategy both variables must be estimated. The estimators designed for this purpose, as well as the corresponding controls, are described in this section.

\section{A. Speed and turbine torque estimation}

The relationship between the mechanical power, which is given by the wind turbine rotor speed and torque, and the electrical power, which is given by the rectified voltage and boost converter current, cannot not be easily obtained from an analytical model. This is mainly due to fact that the passive rectifier does not guarantee unity power factor operation. A commissioning process of both the generator and the rectifier is performed in to obtain an experimental model. For this purpose, the generator is externally driven at different speeds and different boost current commands. The average rectifier voltage and the load torque are measured at steady-state. For the process followed in this work, the speeds varied from $200 \mathrm{rpm}$ to $900 \mathrm{rpm}$ in $50 \mathrm{rpm}$ steps, while the currents varied from $0.5 \mathrm{~A}$ to $10 \mathrm{~A}$ in $0.5 \mathrm{~A}$ steps. Fig. 5 shows the collected data.

Curve fitting is used to obtain a polynomial expression from the results shown in Fig. 5 (4).

$$
\begin{gathered}
\hat{\omega}_{r m}\left(v_{r}, i_{b}\right)=a_{00}+a_{10} v_{r}+a_{01} i_{b}+a_{11} v_{r} i_{b}+ \\
a_{02} i_{b}^{2}+a_{12} v_{r} i_{b}^{2}+a_{03} i_{b}^{3}
\end{gathered}
$$

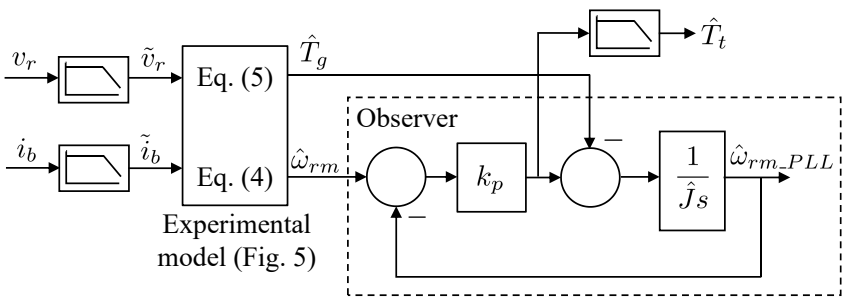

Fig. 6: Block diagram of the turbine torque observer.

where $a_{i j}$ are the polynomial coefficients.

It is seen from Fig. 5(b) that the effect of the rectifier voltage on the generator torque is small and can be therefore safely neglected. The function modeling the torque in terms of the boost current can be simplified to (5).

$$
\hat{T}_{g}\left(i_{b}\right)=a_{1} i_{b}+a_{2} i_{b}^{2}
$$

where $a_{1}$ and $a_{2}$ are the polynomial coefficients.

The current command can be obtained from the torque command using (6). This mathematically corresponds to the inverse function of (5).

$$
i_{b}^{*}=b_{0}+b_{1} T_{g}^{*}+b_{2} T_{g}^{* 2}
$$

It is noted that the independent term $b_{0}$ has no equivalence in (5). This term is given by the curve fitting function, having a small value.

The main limitation of the experimental model is the sensitivity to changes in the electrical machine parameter with temperature, this discussed in Section V. The model could therefore be improved by repeating the commissioning process at different temperatures. The temperature sensor typically used for protection could be later used during normal operation to interpolate between the outputs of the different functions. However, reasonable accuracy was obtained without considering the effects of temperature, as will be shown in section $\mathrm{V}$.

It is finally noted that it is possible to accurately estimate the rotor speed from the rectifier voltage ripple [18], avoiding therefore the need of an accurate model for the speed.

The turbine torque can be estimated from the rotor speed and the generator torque using the observer shown in Fig. 6. The rectified voltage, $v_{r}$, and the boost current, $i_{b}$, are lowpass filtered to be used as inputs, $\tilde{v}_{r}$ and $\tilde{i}_{b}$, to the polynomial interpolation functions (4) and (5) providing the rotor speed, $\hat{\omega}_{r m}$, and the generator torque, $\hat{T}_{g}$ respectively.

The estimated generator torque and rotor speed are then used as inputs for a turbine torque observer as can be seen in Fig. 6. A proportional controller forces the output of the turbine mechanical system model, $\hat{\omega}_{r m_{-} P L L}$, to converge with the estimated speed, $\hat{\omega}_{r m}$, which is used as the reference. The estimated generator torque, $\hat{T}_{g}$, is a disturbance to the mechanical model, where $\hat{J}$ is the total system inertia constant. Therefore, the output of the controller will be the estimated turbine torque. A low-pass filter is used to remove high frequency noise to finally obtain $\hat{T}_{t}$.

While similar concept has been used in [6] to obtain the aerodynamic power of the wind turbine to avoid unstable behaviors during soft-stall, the model presented in this paper includes substantial implementation differences. In [6] the speed was estimated using a fixed back-emf 


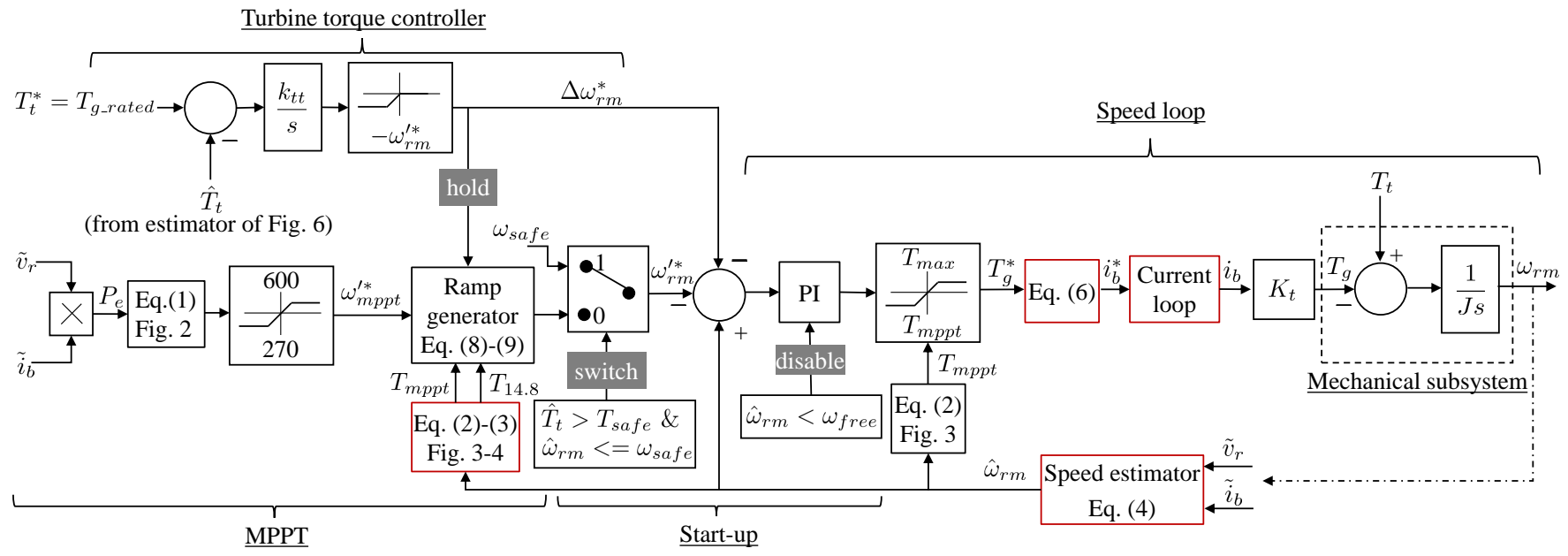

Fig. 7: Block diagram of the rotor speed and torque control.

constant, which can give poor results under high loaded conditions. Moreover, the generator torque is estimated by dividing the electrical power by the speed estimate, which can produce further errors. Finally, the use of a proportional (P) controller is proposed here instead of a proportional-integral (PI) controller as in [6]. The proportional controller provides several advantages: it is simpler to tune; it can capture the turbine torque with faster (and simpler) dynamics; the speed estimation steady-state error is negligible even with moderate proportional gains; and the steady-state error of the torque estimation is zero.

\section{B. Speed and turbine torque control}

The wind generation control block diagram can be seen in Fig. 7. It consists of a main speed control loop, MPPT reference generator and turbine torque controller. All these blocks are discussed following.

1) Speed loop: The speed control loop is shown in the right side of Fig. 7. The overall speed command results from combining the references provided by the MPPT block and by the turbine torque controller (7), the feedback signal being the estimated speed (4). A PI controller with antiwindup is used for speed control. The output torque of the controller is bounded between $T_{\max }$ and the torque required to balance the turbine torque in the MPPT region $T_{m p p t}$, which is obtained from (2). $T_{m p p t}$ is seen to be a function of the rotor speed, and it is used as a feed-forward term aimed to guarantee that a minimum power is generated when tracking the MPPT trajectory. The resulting torque command, $T_{g}^{*}$, is converted into a boost converter current command using the model in (6). The current control loop described in section II guarantees that the generator produces the necessary braking torque to counteract the turbine torque. It is noted that the sign reversal in the generator torque is compensated for by reversing the command and feedback signs in the summing block.

$$
\omega_{r m}^{*}=\omega_{r m}^{* *}+\Delta \omega_{r m}^{*}
$$

2) Start-up: During the turbine start-up, the PI controller is disabled until the estimated speed equals $\omega_{\text {free }}$, as can be seen in Fig. 7. As already explained, this is needed both to allow the rectifier voltage to increase to a minimum level, and to give time for the speed and turbine torque estimators for their initial convergence. Once $\omega_{\text {free }}$ is reached, the PI is enabled and the speed command is initially set to $\omega_{\text {safe }}$, this is done by the switch block of Fig. 7. During this process, the estimated turbine torque is supervised. For values of the torque greater than $T_{\text {safe }}$ (i.e. wind speeds higher than $21 \mathrm{~m} / \mathrm{s}$ ), the speed command is limited to $\omega_{\text {safe }}$. This protects the wind turbine against wind speeds large enough to produce a turbine torque higher than the maximum generator torque. When the torque decreases below $T_{\text {safe }}$, the speed command is switched to the MPPT block.

3) MPPT command generator: The actual electrical power, $P_{e}$, is calculated from the low-pass filtered rectifier voltage, $\tilde{v}_{r}$, and the boost current, $\tilde{i}_{b}$. A speed command reference, $\omega_{m p p t}^{\prime *}$, can be obtained from this power using (1), as shown in Fig. 2. This speed reference is not directly commanded to the speed controller but smoothed using a ramp generator (8) (see Fig. 7).

$$
\omega_{m p p t}^{*}(k)=\omega_{m p p t}^{*}(k-1) \pm \Delta \omega_{m p p t}^{*}(k)
$$

The speed reference increment/decrement will depend on the corresponding turbine torque for a wind speed of $14.8 \mathrm{~m} / \mathrm{s}$ ( $T_{14.8}$ in Fig. 4) (3), and the minimum torque imposed by the generator, $T_{m p p t}$. The speed reference step increase can be calculated using (9), $\hat{J}$ being the system mechanical inertia, and $T_{s}$ the digital controller sampling time.

$$
\Delta \omega_{m p p t}^{*}(k)=\left(T_{14.8}-T_{m p p t}\right) T_{s} / \hat{J}
$$

For wind speeds below $14.8 \mathrm{~m} / \mathrm{s}$ the rotor speed will accelerate at a slower pace than the one imposed by this speed ramp, provided $T_{t}<T_{14.8}$, and the PI controller output would be zero. However, this output is inferior limited to $T_{m p p t}$ to extract some power during the MPPT transients.

Wind speeds above $14.8 \mathrm{~m} / \mathrm{s}$ will make the turbine torque unavoidably surpass the generator rated torque at some rotor speed, as can be seen in Fig. 4. In this case the speed command will be limited by the turbine torque controller as follows. The speed commanded by the ramp generator anticipates this situation by making the PI controller to increase the generator torque to limit the rotor acceleration 
to $\left(T_{14.8}-T_{m p p t}\right) / J$. This will reduce the rotor speed overshoot once the rotor speed matches the commanded speed, and consequently the risk of the turbine torque becoming significantly larger than the generator torque.

4) Turbine torque controller: The turbine torque control consists of an integral (I) controller and a saturation block. The I controller is preferred instead of a PI controller to slow dynamics, as too fast dynamics might produce unacceptable torque magnitudes in the generator. If the estimated turbine torque is below the generator rated torque, the output of the controller is disabled by setting it to zero. When the turbine torque surpasses the generator torque the rotor speed must be decreased and the controller delivers a negative speed command, $\Delta \omega_{r m}^{*}$, that is added to the current MPPT command (7). The ramp generator is stopped in this case to avoid conflicts between MPPT control and torque control ("hold" block in Fig. 7).

\section{Stability analysis}

Stability of the proposed controllers has been studied by developing small-signal models of both the speed control loop and the turbine torque control loop. Estimation errors in the generator parameters are considered. It must be noted that a variation on the turbine parameters modifying the characteristic curves can bring errors in tracking the maximum power trajectory, as in all model-based methods, but they do not affect the stability of the proposed control method neither the protection against high wind speeds:

- A change in the air density due to temperature, humidity, or pressure changes, will decrease or increase the power curves seen in Fig. 2. Therefore, the actual MPPT trajectory would be equally displaced. Due to the flatness seen of the power curves around their maximum value, large errors in tracking the maximum power output are not expected. However, this will depend on the turbine characteristics. A perturband-observe $(\mathrm{P} \& \mathrm{O})$ method could be implemented for MPPT if large errors were expected at the cost of a reduced MPPT convergence speed. This would only change the block providing $\omega_{m p p t}^{*}$ in Fig. 7. In addition, $T_{m p p t}$ should be removed or reduced to implement $\mathrm{P} \& \mathrm{O}$.

- Passive stall of the turbine at high wind speeds would be beneficial for the turbine protection since the torque decreases respect the predicted by the turbine curves.

- Dynamic stall effects in the turbine can produce variations in the expected turbine torque during fast deceleration but they do not prevent the proposed control method from working or pose a risk for stability since they are filtered by the large turbine inertia, their effect being similar to wind gusts.

1) Speed loop stability: The block diagram for the smallsignal model of the speed control loop can be seen in Fig. 8.

The generator torque control loop can be approximated by first order system with a pole at $1 / \tau_{c l}$, corresponding to the bandwidth of the current control loop, the DC gain $1 / k_{e t}$ accounting for the generator torque steady-state estimation error (per unit) (10).

$$
e_{e t}=1-k_{e t}, \text { being } k_{e t}=\frac{\hat{T}_{g \infty}}{T_{g \infty}}
$$

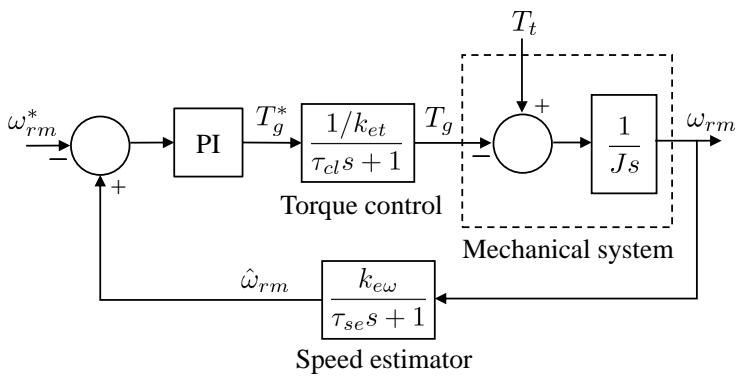

Fig. 8: Small-signal model of the speed control loop.

$\mathrm{Gm}=45.4 \mathrm{~dB}($ at $437 \mathrm{rad} / \mathrm{s}), \mathrm{Pm}=68.2 \mathrm{deg}($ at $16.3 \mathrm{rad} / \mathrm{s})$
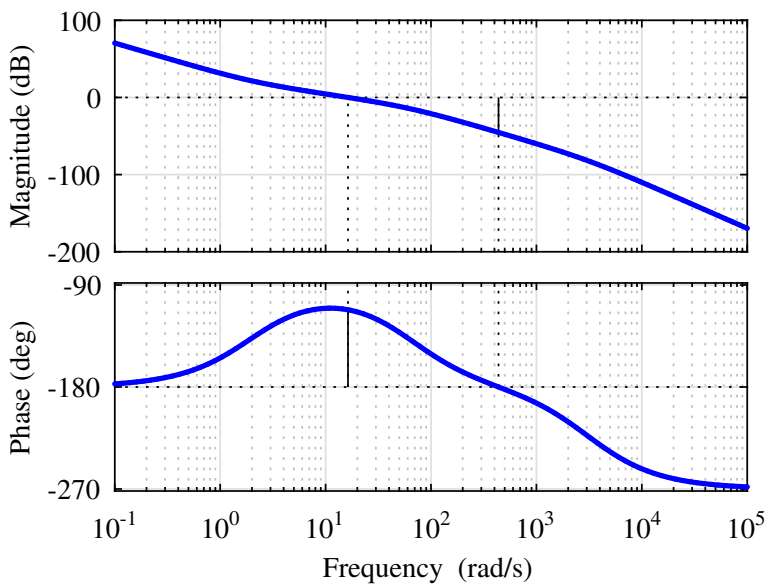

Fig. 9: Bode diagram of the speed control loop indicating the stability margins: Phase margin $(\mathrm{Pm})$ and gain margin $(\mathrm{Gm})$.

where $\infty$ stands for steady-state values.

The speed estimator dynamics are dominated by the voltage and current low-pass filters seen in Fig. 6. Therefore, $1 / \tau_{\text {se }}$ will be the cut-off frequency of those filters. The DC gain $k_{e \omega}$ accounts for the per unit steady-state rotor speed estimation error (11).

$$
e_{e \omega}=1-k_{e \omega}, \text { being } k_{e \omega}=\frac{\hat{\omega}_{r m \infty}}{\omega_{r m \infty}}
$$

Stability margins can be obtained from the Bode diagram of the speed control loop transfer function. Fig. 9 shows the Bode diagram when the PI controller has been set to achieve a closed-loop bandwidth of $2 \mathrm{~Hz}$ and $5 \%$ overshoot in the step-response. The current controller is tuned for a $500 \mathrm{~Hz}$ bandwidth, the low-pass filters have a cut-off frequency of $10 \mathrm{~Hz}$. No steady-state estimation errors are considered in the ideal case.

As can be seen in Fig. 9 a gain increase of $45.4 \mathrm{~dB}$ (186.2 p.u.) is required to make the system unstable. Therefore, the speed and torque estimation errors are unlikely to make the system unstable. Moreover, parameter changes make the torque and speed estimation errors increase or decrease in the same direction (i.e. both speed and torque are either overestimated or underestimated), their effects in the loop gain compensating for each other.

2) Turbine torque loop stability: Similarly to the speed control loop, a small-signal model can be developed for the turbine control loop, as shown in Fig. 10. 


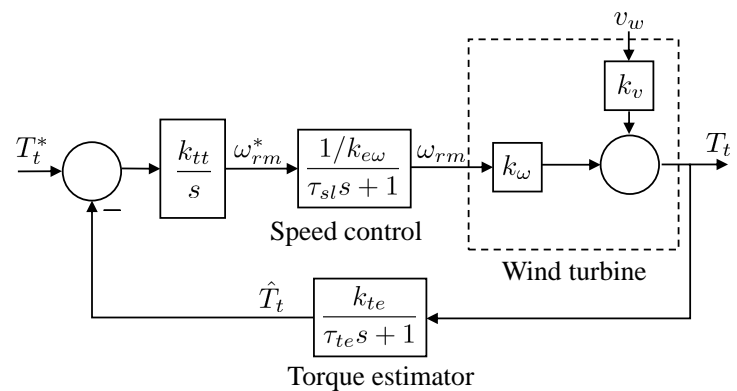

Fig. 10: Small-signal model of the turbine torque control loop.

Provided that the integral controller is tuned to achieve a low bandwidth, the speed control loop can be modeled as a first order system of bandwidth $1 / \tau_{s l}$ and DC gain $1 / k_{e w}$. The dynamics of the turbine torque observer are limited by the low-pass filters of the rectifier voltage and boost current, as shown in Fig. 6. Therefore, $1 / \tau_{t e}$ will be the cut-off frequency of those filters. The turbine torque estimation error in steady-state is equal to the generator torque estimation error $k_{e t}(10)$, since the turbine and generator torques must be balanced to maintain constant speed. The effects of the speed and torque estimators on the closed-loop stability can be analyzed as for the speed control loop. However, in this case the stability and the system dynamics are mainly dictated by the nonlinear behavior of the wind turbine. The wind turbine nonlinear model can be graphically seen in Figs. 3 and 4. A linearized model, shown in Fig. 10, is obtained for the stability analysis (12)-(13).

$$
\begin{aligned}
& k_{\omega}=\left.\frac{\partial T_{t}\left(\omega_{r m}, v_{w}\right)}{\partial \omega_{r m}}\right|_{o p} \\
& k_{v}=\left.\frac{\partial T_{t}\left(\omega_{r m}, v_{w}\right)}{\partial v_{w}}\right|_{o p}
\end{aligned}
$$

where $v_{w}$ is the wind speed and 'op' stands for operating point.

The magnitude of $k_{v}$ is irrelevant for the analysis of the loop stability as it does not affect to the control loop. On the contrary, the rotor speed dependent constant $k_{\omega}$ will have a significant impact on the closed-loop stability and dynamics. For a given wind speed, this constant is the slope of the torque vs. speed curves seen in Figs. 3 and 4. For the sake of clarity it has been calculated for the wind speeds of Fig. 4, being shown in Fig. 11.

Three situations can occur:

1) $k_{\omega}<0$. This corresponds to the negative-slope region in the curves shown in Figs. 3 and 4, or negative values in Fig. 11. In this situation, the positive feedback makes the torque control loop unstable. Fortunately, this not poses a dangerous situation. This means that if a turbine torque magnitude can be potentially achieved at both sides of the torque curve (for a given wind speed) it cannot never be balanced at the right side with the implemented turbine torque control loop. In practice, the negative sign indicates that decreasing the rotor speed makes the turbine torque to increase until the peak torque is reached.

2) $k_{\omega}=0$. This occurs both at the peak of the torque curves, and at low speeds in Figs. 3 and 4. The system

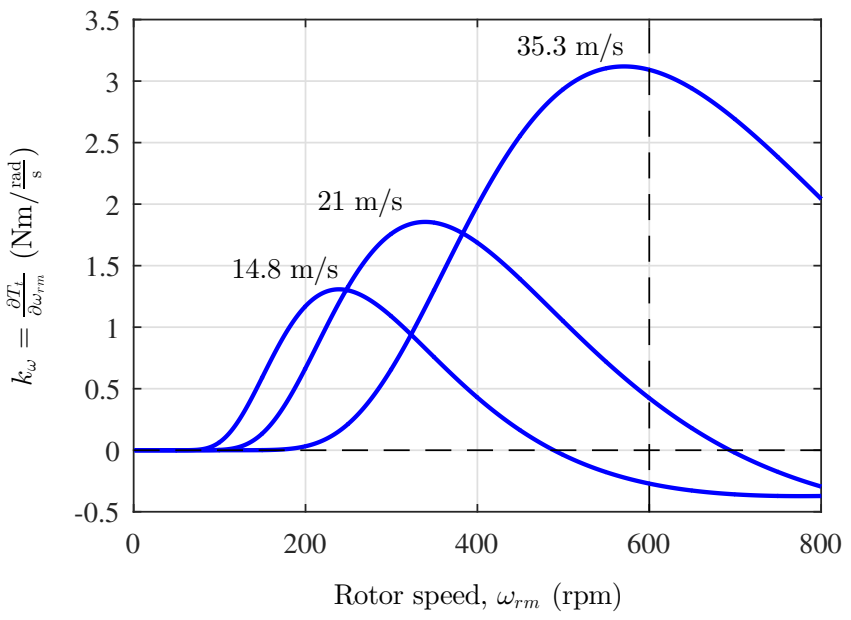

Fig. 11: Partial derivative of the turbine torque at different rotor and wind speeds.

$\mathrm{Gm}=34.5 \mathrm{~dB}($ at $28.1 \mathrm{rad} / \mathrm{s}), \mathrm{Pm}=82.3 \mathrm{deg}($ at $1.42 \mathrm{rad} / \mathrm{s})$
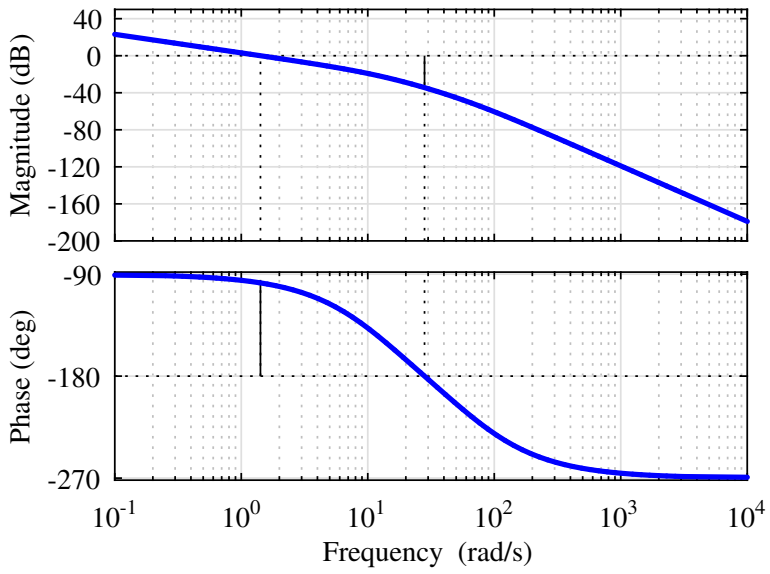

Fig. 12: Bode diagram of the turbine torque loop function indicating the stability margins: Phase margin $(\mathrm{Pm})$ and gain margin $(\mathrm{Gm})$.

is marginally stable in this case. The loop dynamics become slow since small variations of the rotor speed have no impact on the turbine torque due to the low (zero) loop function gain.

3) $k_{\omega}>0$. This corresponds to the positive-slope torque region. The system stability analysis can be performed using the loop function in this case.

For the tuning of the integral controller $k_{\omega}$ has been selected according to the largest derivative for the $21 \mathrm{~m} / \mathrm{s}$ curve in Fig. 11. This corresponds to the largest wind speed which can be controlled in the whole rotor speed range. The integral controller has been tuned to achieve a closed-loop bandwidth of $0.25 \mathrm{~Hz}$. The speed loop bandwidth has been set to $2 \mathrm{~Hz}$ and the turbine torque estimator bandwidth is $10 \mathrm{~Hz}$. The corresponding Bode diagram of the loop function can be seen in Fig. 12.

The gain margin in this case is $34.5 \mathrm{~dB}$ (53 p.u.), meaning that even large variations in the estimation errors as well as in the wind speed will not jeopardize 


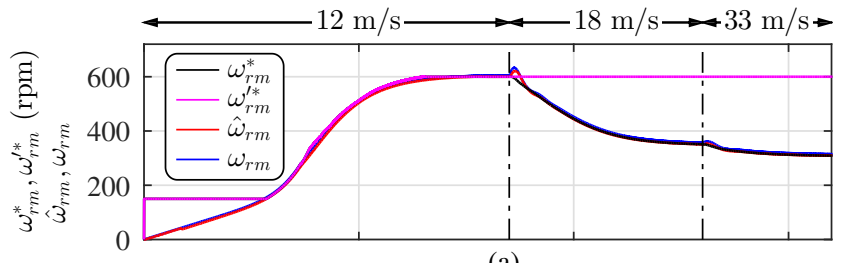

(a)
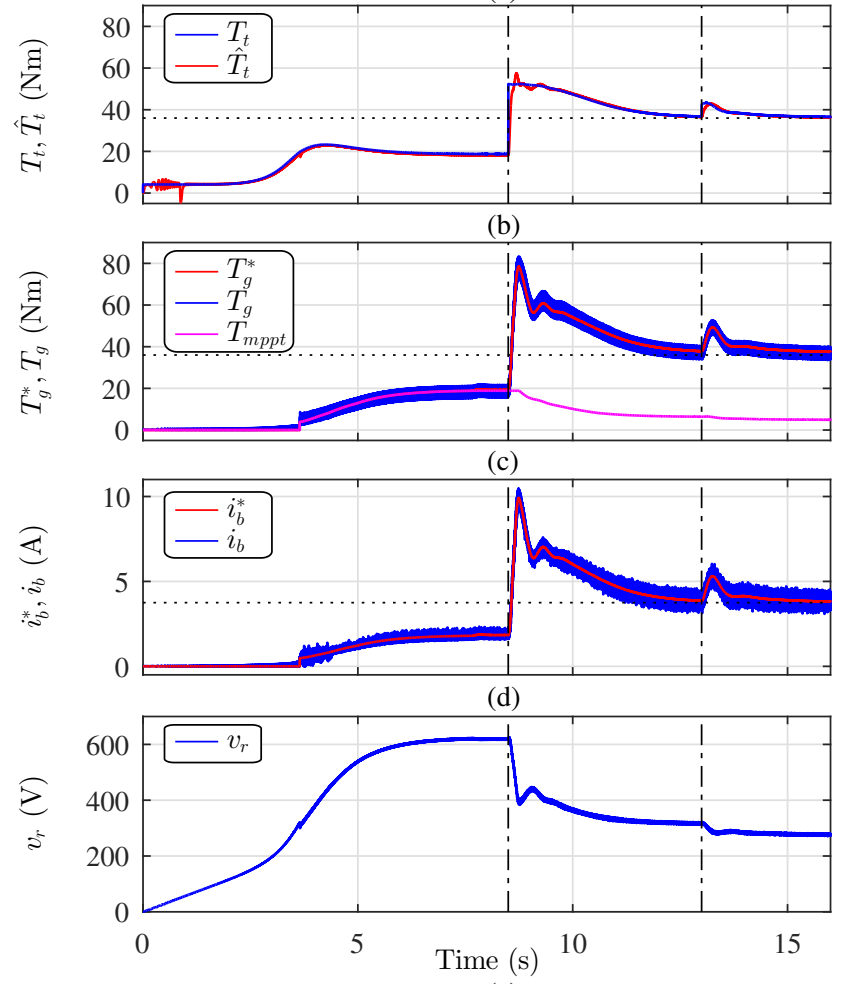

(e)

Fig. 13: Simulation results with correct parameter estimates. Response of the proposed method under with increasing wind speed $(12,18$ and 33 $\mathrm{m} / \mathrm{s}$ ). a) Rotor speed command, rotor speed command (before turbine torque controller), estimated rotor speed, actual rotor speed; b) Turbine torque and estimated turbine torque; c) Generator torque command and generator torque; d) Boost current command and boost current; e) Rectifier voltage.

the system stability. For instance, the largest derivative for a wind speed of $35.3 \mathrm{~m} / \mathrm{s}$ is $3.1 \mathrm{Nm} /(\mathrm{rad} / \mathrm{s})$, the resulting increase in the loop gain being only $1.7 \mathrm{p} . \mathrm{u}$.

\section{Simulation Results}

The performance of the proposed turbine control has been tested first by means of simulation, Powersim PSIM using the hardware description shown in Fig. 1 has been used for this purpose. The control loops have been implemented in a $\mathrm{C}$ language block for easiness of portability to a microcontroller. The most significant turbine and generator parameters can be found in Tables I-II.

\section{A. Operation with correct parameter estimates}

The performance of the proposed control method under increasing wind conditions can be seen in Fig. 13. The system starts with a wind speed of $12 \mathrm{~m} / \mathrm{s}$. At $t=8.5 \mathrm{~s}$ the wind speed increases to $18 \mathrm{~m} / \mathrm{s}$, and at $t=13$ to $33 \mathrm{~m} / \mathrm{s}$. While such speed step changes are not realistic in a real system, they are useful to evaluate the dynamic behavior of the proposed control methods. The speed reference $\omega_{r m}^{*}$ is initially set to $\omega_{\text {safe }}=170 \mathrm{rpm}$ (Fig. 13(a)). The estimated turbine torque $\hat{T}_{t}$ quickly converges to the actual turbine torque (Fig. 13(b)). The estimated speed, $\hat{\omega}_{r m}$, matches quite precisely with the actual speed during the whole process. Once the speed reaches $170 \mathrm{rpm}$, and since the turbine torque is under $T_{\text {safe }}$, the speed reference will be switched to MPPT. Since the speed reference slope is based on a wind speed of $14.8 \mathrm{~m} / \mathrm{s}$, no generator torque will be required until $270 \mathrm{rpm}$, as can be seen in Fig. 13(c).

Once the MPPT region is reached at $270 \mathrm{rpm}$, a minimum torque command of $T_{m p p t}$ will be imposed to start generating while the system tracks the MPPT trajectory. The wind speed change occurring at $t=8.5 \mathrm{~s}$ will increase the turbine torque above the generator rated value (dotted line in Fig. 13(b)). This overload can be withstood by the generator for a certain time. The turbine torque controller is then enabled, decreasing the speed reference. At this point $\omega_{r m}^{\prime *}$ is held constant while $\omega_{r m}^{*}$ decreases, and thus, the rotor speed also decreases (Fig. 13(a)). This makes the turbine torque to converge to the generator rated torque and consequently, the generator torque and current return to rated values (Fig. 13(c)-(d)).

The second wind speed change $(t=13 s)$ increases the turbine torque, the control reacting to lower the rotor speed. It is noted that the generator torque $T_{g}$ closely matches the torque command, $T_{g}^{*}$, as the torque to current model (6) uses accurate parameters. It can be seen from Fig. 13(e) that the rectifier voltage is indirectly controlled during the whole process.

It is interesting to note that if the wind speed increases from $12 \mathrm{~m} / \mathrm{s}$ to $33 \mathrm{~m} / \mathrm{s}$ would have arisen at $8.5 \mathrm{~s}$ the system would have not been able to brake the rotor since the turbine torque would have surpassed the short-time maximum torque of the generator. In that case, an external brake system should have been activated.

Fig. 14 shows the response of the proposed method when the wind speed decreases. The system start-up occurs with a wind speed of $33 \mathrm{~m} / \mathrm{s}$. The rotor speed rapidly increases to $\omega_{\text {safe }}$. Since the estimated torque is above $T_{\text {safe }}$, the speed command is held constant (Fig. 14(a)-(b)). It can be observed from Fig. 14(b) that after an initial transient the estimated torque closely follows the actual turbine torque. At $t=4 \mathrm{~s}$ the wind speed decreases to $18 \mathrm{~m} / \mathrm{s}$ and thus, the turbine torque also decreases. Therefore, the speed reference is increased to follow the MPPT trajectory. The speed variation can be larger than that provided by the speed command ramp, a torque demand slightly larger than $T_{m p p t}$ occurs in this case, as can be seen in Fig. 14(c). Sudden variations in the generator torque are seen in Fig. 14(b) to produce a distortion in the estimated turbine torque. However, this does not compromise the performance of the proposed method. As the rotor speed increases, the turbine torque increases too, eventually surpassing the rated torque. As a consequence, the torque control is again enabled, the turbine torque reducing to its rated value. At $t=11 \mathrm{~s}$ the wind speed decreases to $12 \mathrm{~m} / \mathrm{s}$ and the torque controller is disabled, what resumes MPPT operation.

\section{B. Operation with incorrect parameter estimates}

The generator parameters can largely change during normal operation, mainly due to temperature variations. An increase in the generator temperature induces an increase of the stator 


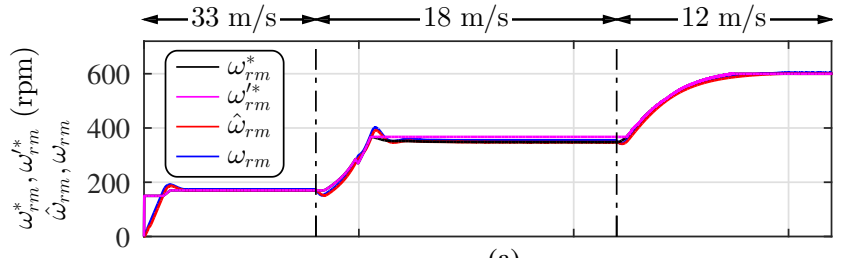

(a)

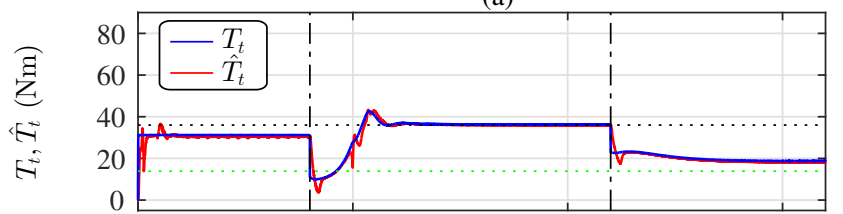

(b)

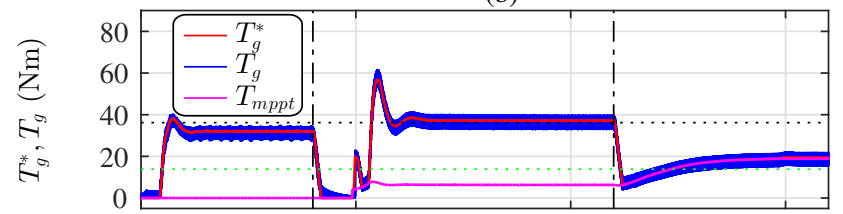

(c)

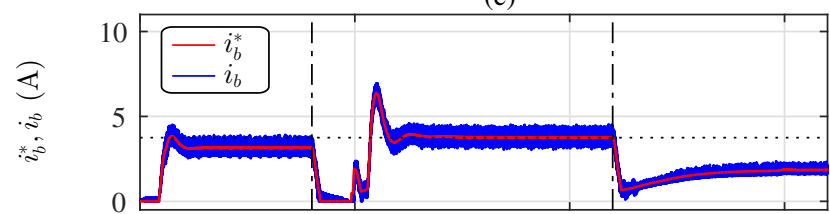

(d)

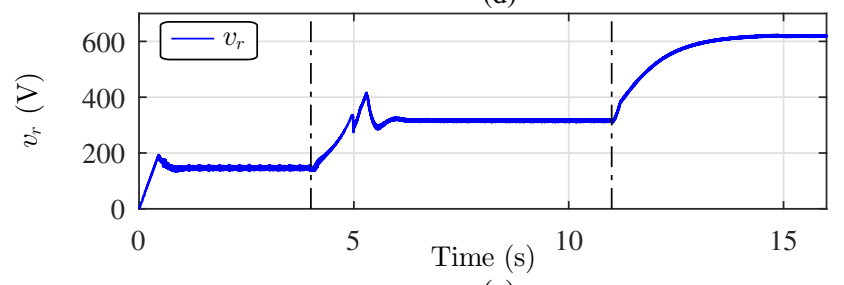

(e)

Fig. 14: Simulation results with correct parameter estimates. Response of the proposed method under with decreasing wind speed $(33,18,12 \mathrm{~m} / \mathrm{s})$. Same legends as in Fig. 13.

resistance and a decrease of the magnets strength. This will affect to the generator torque production capability, as well as to the magnetic saturation and consequently to the inductances [19]-[21]. An increase in the generator temperature has been studied using a Finite Element Analysis (FEA) software package, three different machine thermal states (20, 60 and $100{ }^{\circ} \mathrm{C}$ ) were simulated. The same machine to be used for the experimental verification was used for FEA. Table III shows the summary of the FEA. It is observed that an $80{ }^{\circ} \mathrm{C}$ temperature rise in the generator temperature results in an increase of $32.3 \%$ in the generator winding resistance and in a $9.6 \%$ reduction of the back-emf constant $k_{e}$, which induces a variation of $\approx 0.22 \%$ in $L_{q}$ and $\approx 1.11 \%$ in $L_{d}$. It can be concluded from these results that although the machine thermal state has a relatively large impact on the machine stator resistance, the low impact on the back-emf and almost negligible impact on the machine inductances make the proposed method highly insensitive from thermal aspects.

Fig. 15 show the same results as in Fig. 13 when there are errors in the parameters estimates. The controllers' gains have not been changed.

It can be seen that the control is perfectly stable, still some differences exist with respect to the results shown in Fig. 13. The rotor speed is underestimated i.e $\hat{\omega}_{r m}<\omega_{r m}$

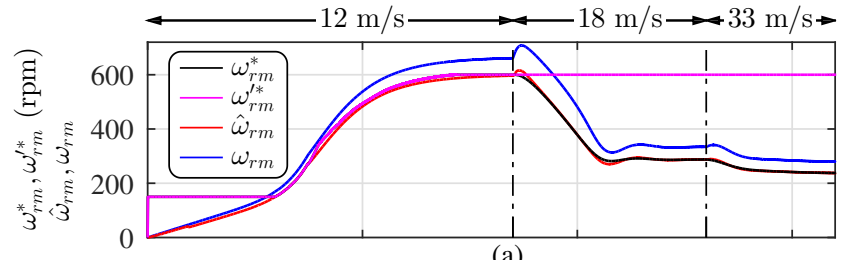

(a)
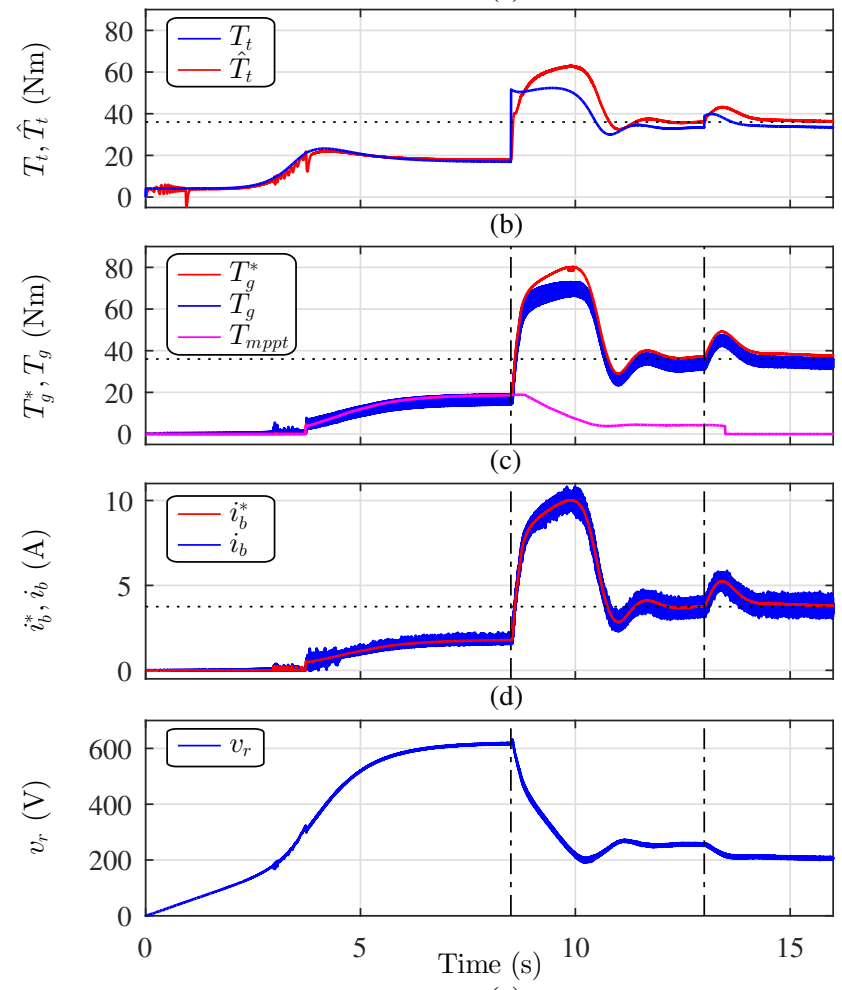

(e)

Fig. 15: Simulation results when the machine operates at a temperature of $100{ }^{\circ} \mathrm{C}$. Same operating conditions and legends as in Fig. 13.

TABLE III: Parameter change (FEA analysis)

\begin{tabular}{|c|c|c|c|}
\hline Temp $\left({ }^{\circ} \mathrm{C}\right)$ & 20 & 60 & 100 \\
\hline$k_{e}\left(\mathrm{~V}_{\text {peak }} / \mathrm{rpm}\right)$ & 1,188 & 1,131 & 1,074 \\
\hline$R_{s}(\Omega)$ & 6,3 & 7,32 & 8,35 \\
\hline$L_{q}(\mathrm{mH})$ & 67,32 & 67,42 & 67,47 \\
\hline$L_{d}(\mathrm{mH})$ & 65,8 & 66,23 & 66,54 \\
\hline
\end{tabular}

(Fig. 15-(a)), though both show a similar dynamic behavior. The estimated turbine torque, $\hat{T}_{t}$, closely follows the actual value except for very high torque situations (Fig. 15(b)).The generator torque is overestimated, especially at high torque values, as can be seen in Fig. 15(c), which produces an error in the estimated turbine torque. The large current required to bring the turbine to its rated torque values last longer than in Fig. 13. This is mainly due to the reduced torque produced by the generator for the same current level, as the magnet strength has decreased. Finally, it must be remarked that the actual speed excursion above $600 \mathrm{rpm}$ seen in Fig. 15(a) does not produce over voltages (Fig. 15(e)). This is due to the decreased back-emf constant and the increased stator resistance. 


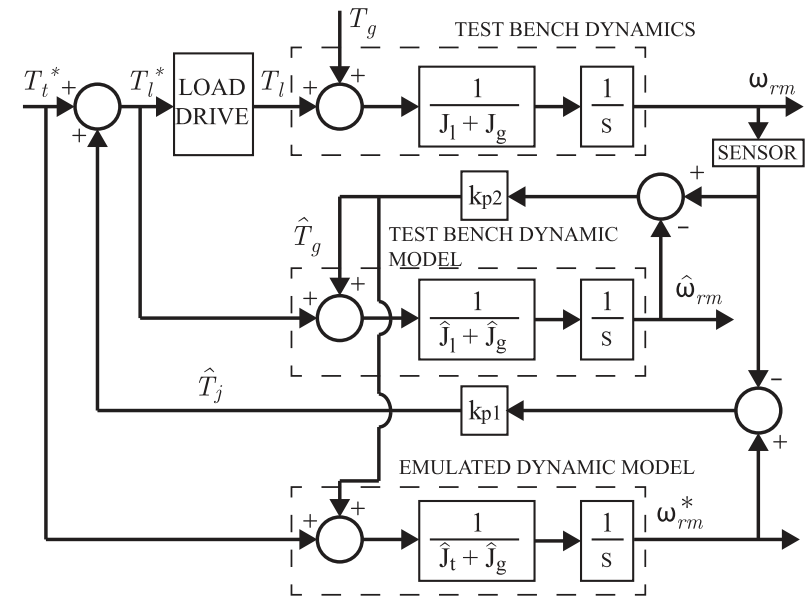

Fig. 16: Block diagram of inertia emulator - Method 1.

\section{INERTIA EMULATION}

A relevant aspect for the experimental evaluation of control methods for wind turbines is the emulation of the turbine behavior. Steady-state models which provide the turbine power or torque for a certain wind speed and rotor speed are often used [22]. This torque/power are then commanded to the load drive. A limitation of this approach is that it disregards the effects of the turbine inertia. The inclusion of the system inertia to obtain more reliable results has also been explored in the literature [9]-[11], [13]-[15]. The methods proposed in [14], [15] have the advantage of not requiring generator torque measurements by estimating the generator torque. However, the method proposed in [15] is more robust than that in [14] by avoiding derivative operations. Unfortunately, the dynamic performance of that method as well as the gain tuning have not been clearly established.

Two new inertia emulation methods are proposed in this section. They add to benefits of [15] a well-defined dynamic behavior, a simple commissioning process and easiness of implementation.

\section{A. Method 1}

The block diagram of method 1 can be seen in Fig. 16. The following description of the main blocks also applies to method 2. The torque controlled "load drive" emulates the wind turbine behavior, its input being a load torque command, $T_{l}^{*}$. The actual permanent magnet generator will impose a torque $T_{g}$ which is dictated by its own controller. The mechanical model of the actual test bench results from the combined effect of load machine, $J_{l}$, and the permanent magnet generator inertia, $J_{g}$ ("test bench dynamics" block in Fig. 16). Test bench dynamics ("test bench dynamic model" in Fig. 16), and wind turbine dynamics ("emulated dynamic model") are modeled by software to emulate the wind turbine inertia. A turbine torque command, $T_{t}^{*}$, is provided in both methods by a turbine model based on the wind speed command and the actual rotor speed as shown in Figs. 3 and 4.

The turbine torque command, $T_{t}^{*}$, is applied both to the "test bench dynamics" and the "emulated dynamic model". As they have different inertia constants, their output speed will be also different. The output of the "emulated dynamic

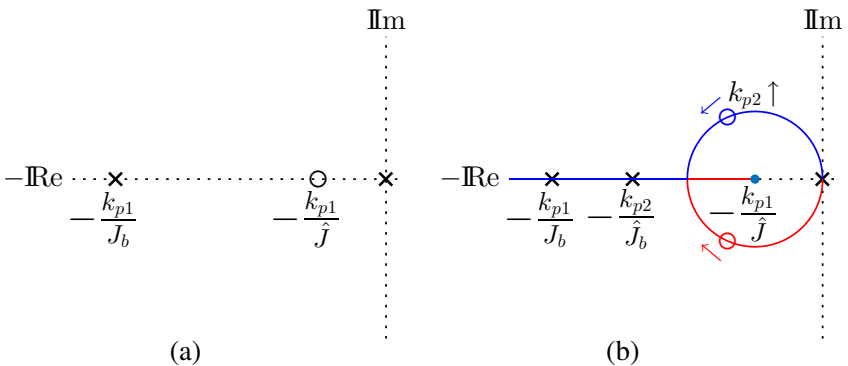

Fig. 17: S-plane pole-zero map of the transfer functions of method 1: a) $\omega_{r m}(s) / T_{t}^{*}(s)$; b) $\omega_{r m}(s) / T_{l}(s)$

model" can be used as a speed command for the load drive, $\omega_{r m}^{*}$. A proportional controller $k_{p 1}$ is used to force the convergence between both speeds. The output of this controller is the torque absorbed by the large inertia, $\hat{T}_{j}$, and is added to the turbine torque command, to generate the load drive torque command, $T_{l}^{*}$. However, the speed difference can also be produced by the generator torque. Therefore, this torque must be estimated and used as an input in the "emulated dynamic model".

The load torque command, $T_{l}^{*}$ is also applied to the "test bench dynamic model". The output of this model is a speed estimate, $\hat{\omega}_{r m}$. The difference with the actual speed is due to the generator torque, $T_{g}$. A proportional controller $k_{p 2}$ will force both signals to converge by adding the output of this controller to the "test bench dynamic model input". This output is the generator torque estimate, $\hat{T}_{g}$ that is also added to the "emulated dynamic model".

The transfer functions of this emulator are given by (14)(15).

$$
\frac{\omega_{r m}(s)}{T_{t}^{*}(s)}=\frac{\left(\hat{J} s+k_{p 1}\right)\left(\hat{J}_{b} s+k_{p 2}\right)}{\hat{J}_{s}\left(J_{b} s+k_{p 1}\right)\left(\hat{J}_{b} s+k_{p 2}\right)+\left(J_{b}-\hat{J}_{b}\right) k_{p 1} k_{p 2} s}
$$

$$
\frac{\omega_{r m}(s)}{T_{g}(s)}=\frac{\hat{J} \hat{J}_{b} s^{2}+k_{p 2} \hat{J} s+k_{p 1} k_{p 2}}{\hat{J} s\left(J_{b} s+k_{p 1}\right)\left(\hat{J}_{b} s+k_{p 2}\right)+\left(J_{b}-\hat{J}_{b}\right) k_{p 1} k_{p 2} s}
$$

where $J_{b}=J_{l}+J_{g}, \hat{J}_{b}=\hat{J}_{l}+\hat{J}_{g}$ and $\hat{J}=\hat{J}_{t}+\hat{J}_{g}$.

Assuming $\hat{J}_{b} \approx J_{b}$ they can be simplified to (16)-(17)

$$
\begin{gathered}
\frac{\omega_{r m}(s)}{T_{t}^{*}(s)} \approx \frac{\left(\hat{J} s+k_{p 1}\right)}{\hat{J}_{s}\left(J_{b} s+k_{p 1}\right)} \\
\frac{\omega_{r m}(s)}{T_{g}(s)} \approx \frac{\hat{J} \hat{J}_{b} s^{2}+k_{p 2} \hat{J}_{s}+k_{p 1} k_{p 2}}{\hat{J}_{s}\left(J_{b} s+k_{p 1}\right)\left(\hat{J}_{b} s+k_{p 2}\right)}
\end{gathered}
$$

The pole-zero map of the transfer functions (16)-(17) can be seen in Fig. 17. It is observed that the dynamics are dominated by the emulated inertia in both cases. Nevertheless, depending on the controller gains the additional singularities can be weighted in different manners. The turbine torque command to rotor speed transfer function (16) seen in Fig. 17(a) has an additional pole and a zero, being the zero closer to the origin. Ideally, a large $k_{p 1}$ gain will move both the zero and the pole far from the origin of the s-plane making them negligible. In practice, $k_{p 1}$ will be limited by the load drive sampling/control frequency and the zero at $-\frac{k_{p 1}}{\hat{J}}$ 
TABLE IV: Selection of $k_{p 2}$ gain

\begin{tabular}{|c|c|c|}
\hline Zero(es) location (real part) & $k_{p 2}$ - Method 1 & $k_{p 2}$ - Method 2 \\
\hline$-\frac{k_{p 1}}{\hat{J}}$ & $2 k_{p 1} \frac{\hat{J}_{b}}{\hat{J}}$ & $k_{p 1}\left(1-\frac{\hat{J}_{b}}{\hat{J}}\right)$ \\
\hline$-2 \frac{k_{p 1}}{\hat{J}}$ & $4 k_{p 1} \frac{\hat{J}_{b}}{\hat{J}}$ & $2 k_{p 1}\left(1-\frac{\hat{J}_{b}}{\hat{J}}\right)$ \\
\hline$k_{p 1}\left(\frac{1 \pm \sqrt{1+4} \frac{\hat{J}_{b}}{\hat{J}}}{2 \hat{J}_{b}}\right)$ & $k_{p 1}$ & $k_{p 1}$ \\
\hline$-\frac{k_{p 1}}{2 \hat{J}_{b}}$ & - & $\frac{k_{p 1} \hat{J}}{4 \hat{J}_{b}}$ \\
\hline
\end{tabular}

will have a transient effect in the response. The theoretical limit is imposed by the Nyquist theorem (18), being $\omega_{s}$ the sampling frequency. However, a lower value is recommended. If required, an open-loop prefilter can be added to cancel the zero out.

$$
\frac{k_{p 1}}{J_{b}}<\frac{\omega_{s}}{2}
$$

The generator torque to rotor speed transfer function (17) poles and zeroes can be seen in Fig. 17(b). Assuming $k_{p 1}$ has been already fixed, $k_{p 2}$ will move the pole at $-k_{p 2} / \hat{J}_{b}$ and the two zeroes. The zeroes' locations are given by the root contour shown in 17(b). Starting at the origin of the splane, they describe a circular trajectory with center $-k_{p 1} / \hat{J}$, converging in $-2 k_{p 1} / \hat{J}$ in the real axis. Then, one zero moves to $-\infty$ and the other one to $-k_{p 1} / \hat{J}$. Therefore, the convergence point will be the farthest from the origin to locate the zeroes. Table IV shows the value of $k_{p 2}$ to locate the zeroes at the convergence point, as well as other positions for comparison with method 2. It must be remarked that these zeroes cannot be canceled with a prefilter.

\section{B. Method 2}

The second method can be seen in Fig. 18. The turbine torque command, $T_{t}^{*}$, is the input to the "emulated dynamic model". The output of that model is a speed reference for a closed-loop speed controlled "test bench dynamic model". The output of the proportional controller, $k_{p 1}$, will be the required torque for the actual test bench to have a similar response to the emulated system in the absence of generator torque. By forcing to converge the output of the "test bench dynamic model" with the actual output of the test bench using the proportional controller $k_{p 2}$, the generator torque can be estimated. This estimate is then added to the input of the "emulated dynamic model" and subtracted from the torque command provided by the controller $k_{p 1}$. This will intuitively produce a smother transient response than method 1 , provided that the turbine torque command is not directly used to command the load drive.

The transfer functions in this case are given by (19)-(20)

$$
\begin{aligned}
& \frac{\omega_{r m}(s)}{T_{t}^{*}(s)}=\frac{k_{p 1}\left(\hat{J}_{b} s+k_{p 2}\right)}{\hat{J} s\left(J_{b} s+k_{p 2}\right)\left(\hat{J}_{b} s+k_{p 1}\right)+\left(J_{b}-\hat{J}_{b}\right) k_{p 1} k_{p 2} s} \\
& \frac{\omega_{r m}(s)}{T_{g}(s)}=\frac{\hat{J} \hat{J}_{b} s^{2}+k_{p 1} \hat{J} s+k_{p 1} k_{p 2}}{\hat{J}_{s}\left(J_{b} s+k_{p 2}\right)\left(\hat{J}_{b} s+k_{p 1}\right)+\left(J_{b}-\hat{J}_{b}\right) k_{p 1} k_{p 2} s}
\end{aligned}
$$

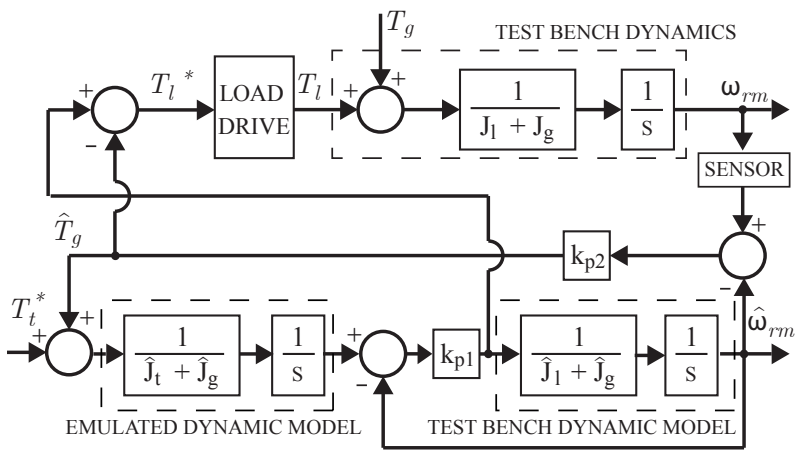

Fig. 18: Block diagram of inertia emulator - Method 2.

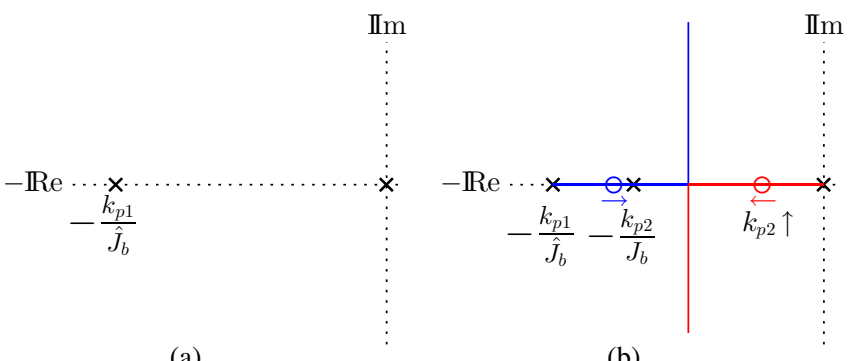

Fig. 19: S-plane pole-zero map of the transfer functions of method 2: a) $\omega_{r m}(s) / T_{t}^{*}(s)$; b) $\omega_{r m}(s) / T_{l}(s)$

And assuming $\hat{J}_{b} \approx J_{b}$, (21)-(22) are obtained.

$$
\begin{gathered}
\frac{\omega_{r m}(s)}{T_{t}^{*}(s)} \approx \frac{k_{p 1}}{\hat{J}_{s}\left(\hat{J}_{b} s+k_{p 1}\right)} \\
\frac{\omega_{r m}(s)}{T_{g}(s)} \approx \frac{\hat{J} \hat{J}_{b} s^{2}+k_{p 1} \hat{J} s+k_{p 1} k_{p 2}}{\hat{J} s\left(J_{b} s+k_{p 2}\right)\left(\hat{J}_{b} s+k_{p 1}\right)}
\end{gathered}
$$

The pole-zero maps of the transfer functions (21)-(22) can be seen in Fig. 19. Fig. 19(a) shows that method 2 provides an improved response with respect to method 1 , as it removes the zero seen in 17(a). Again, $k_{p 1}$ will be selected with the limitation imposed by (18).

The pole-zero map of the generator torque to the rotor speed can be seen in Fig. 19(b). Since $k_{p 1}$ was already tuned, $k_{p 2}$ will move the location of a second pole and the two zeroes. The root contour for the two zeroes has two branches starting one at the origin and the other at $-k_{p 1} / \hat{J}_{b}$. For increasing values of $k_{p 2}$ the closest zero to the origin will displace to the convergence point located at $-k_{p 1} /\left(2 \hat{J}_{b}\right)$. The advantage of this method is this convergence point is farther from the origin than the one for method 1, provided that $J \gg J_{b}$. The disadvantage is that larger $k_{p 2}$ gains are required to locate the dominant zero at similar positions than in method 1. The limit for setting $k_{p 1}$ (18) also holds for $k_{p 2}$. For $k_{p 1}=k_{p 2}$ both methods share the same dynamics. A summary for different $k_{p 2}$ selections can be found in table IV.

The described behavior is seen in the simulation results shown in Fig. 20. The turbine and generator torque profiles are shown in Fig. 20(a). They should ideally produce slopes of value $\left(T_{t}^{*}-T_{g}\right) / J$ in the speed response (blue line in Fig. 20(b). Both methods provide the adequate slope change except for a fast transient dictated by the zeroes in the 

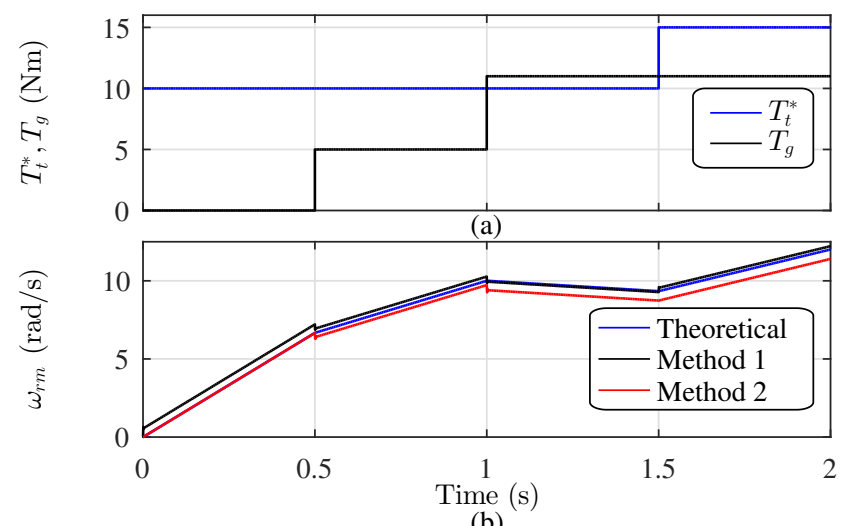

(b)

Fig. 20: Comparison of the proposed system inertia emulators using under step torque changes: a) Turbine torque command and generator torque; b) Resulting rotor speed for each method.

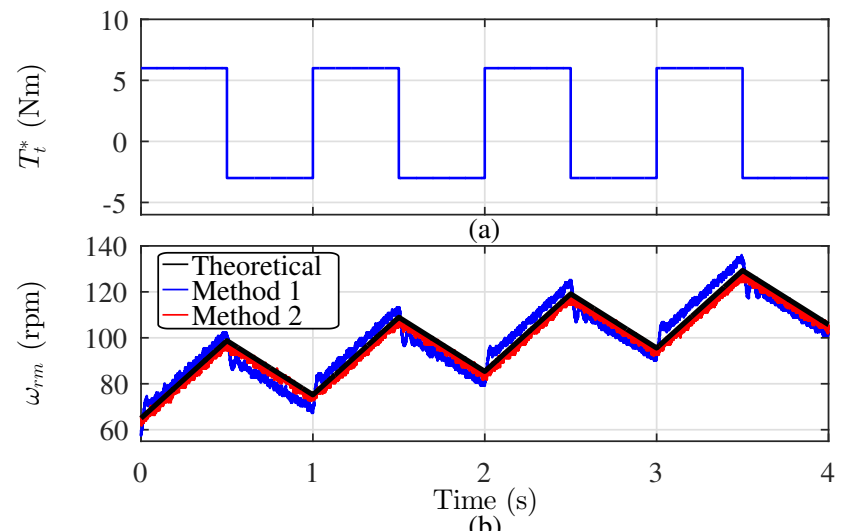

Fig. 21: Comparison of the two inertia emulation methods with zero generator torque and step changes of the turbine torque command, showing: a) Turbine torque command; b) Rotor speed for both methods and theoretical response.

transfers functions. However, method 2 is insensitive to fast changes in the commanded turbine torque, producing almost the same change as the high inertia system. This is an advantage if large torque step changes are to be produced by the turbine torque command, for instance to simulate fast changes in the wind speed. This agrees with the fact the transfer function of method 2 lacks the zero seen in method 1. The advantage of method 1 is that the transients produced by the emulated turbine and the generator compensate for each other in the long term, the actual speed being closer to that of the emulated system if torque is open-loop applied, provided the zero in (16) is not canceled.

\section{EXPERIMENTAL RESULTS}

For the experimental verification of the proposed control methods, the inertia emulator was implemented in a commercial high performance vector controlled drive. The emulated turbine inertia is $0.75 \mathrm{~kg} \mathrm{~m}^{2}$.

Fig. 21 shows the performance of the proposed methods when the generator is not producing any torque. As expected, emulation method 1 shows faster transient response compared to method 2 to changes in the torque command. The transient deviations seen on method 1 largely depend on the controller
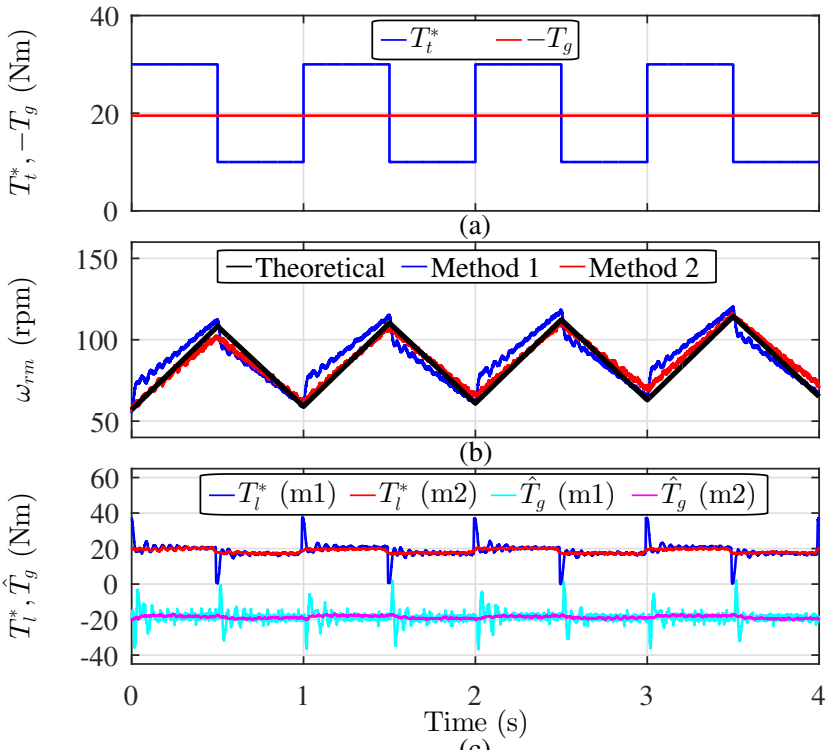

(c)

Fig. 22: Comparison of the two inertia emulation methods with a constant torque of $20 \mathrm{Nm}$ imposed by the generator and step changes in the turbine torque command, showing: a) Turbine torque command; b) Rotor speed for both methods and theoretical response; c) Drive torque command, $T_{l}^{*}$, and estimated generator torque, $\hat{T}_{g}$, for method 1 (m1) and $2(\mathrm{~m} 2)$.

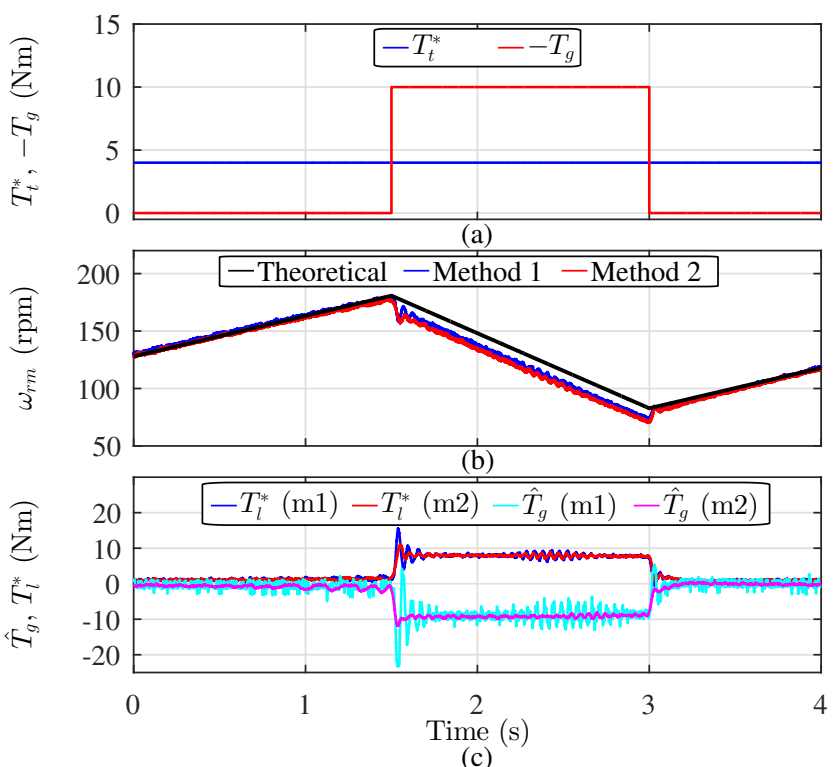

Fig. 23: Comparison of the two inertia emulation methods under a step changes of the generator torque, showing: a) Turbine torque command; b) Rotor speed using both methods; c) Drive torque command, $T_{l}^{*}$, and estimated generator torque, $\hat{T}_{g}$ using method $1(\mathrm{~m} 1)$ and $2(\mathrm{~m} 2)$.

gains, being possible to increase its magnitude with a faster drive sampling frequency. Method 2 is less dependent on the controller gain in absence of generator load. The real poles' location in our setup was limited to $63 \mathrm{rad} / \mathrm{s}(10 \mathrm{~Hz})$ due to controller board limitations.

Fig. 22 shows the speed response under a square-wave torque command between 30 and $10 \mathrm{Nm}$, and a constant generator torque of $20 \mathrm{Nm}$. It is seen that both methods provide a consistent response compared with the theoretical response, despite of the fast transients experienced by 
method 1. Fig. 22(c) shows the estimated load torque, $\hat{T}_{g}$, and the actual torque applied by the motor drive, $T_{l}^{*}$.

The effect of a variable generator torque in the performance of the proposed methods is shown in Fig. 23, where a constant turbine torque command of $4 \mathrm{Nm}$ is applied to the system and a step change is applied in the generator torque. As expected, the speed response is similar for both methods.

\section{CONCLUSIONS}

This paper proposes an advanced method to protect small wind turbines against high wind speeds by controlling the turbine torque. A turbine torque controller is used to force the turbine torque to remain under rated values. A torque observer is used to determine the turbine torque, the inputs for the observer being the rotor speed and the generator torque. The rotor speed and generator torque are obtained from measured electrical variables by using pre-commissioned experimental models. The method allows an early detection of high wind speed situations decreasing the generator stress. Moreover, it maximizes the power extraction in case of high wind speed situations. The stability of the proposed control has been proven even in the case of large estimation errors due to generator parameter changes.

The wind turbine hardware emulation can be improved by the inclusion of inertia emulation. Two methods have been presented for that purpose. They do not require the use of torque measurements nor communications between the load drive and the generator controller. The methods are easy to tune and implement and do not require high computational requirements making them suitable for commercial drives.

\section{REFERENCES}

[1] A. Sugawara, K. Yamamoto, T. Yoshimi, S. Sato, A. Tsurumaki, and T. Ito, "Research for Electric Brake Using NTC Thermistors on Micro Wind Turbine," in Power Electronics and Motion Control Conference, 2006. EPE-PEMC 2006. 12th International, Sep. 2006, pp. 1597 1601.

[2] Y. Matsui, A. Sugawara, S. Sato, T. Takeda, and K. Ogura, "Braking Circuit of Small Wind Turbine Using NTC Thermistor under Natural Wind Condition," in Power Electronics and Drive Systems, 2007. PEDS '07. 7th International Conference on, Nov. 2007, pp. 910 915.

[3] E. Muljadi, T. Forsyth, and C. P. Butterfield, "Soft-stall control versus furling control for small wind turbine power regulation," National Renewable Energy Lab., Golden, CO (United States), Tech. Rep., 1998. [Online]. Available: http://www.osti.gov/scitech/biblio/661575

[4] A. Ahmed, L. Ran, and J. Bumby, "New Constant Electrical Power Soft-Stalling Control for Small-Scale VAWTs," IEEE Transactions on Energy Conversion, vol. 25, no. 4, pp. 1152-1161, Dec. 2010.

[5] Z. Dalala, Z. Zahid, and J.-S. Lai, "New overall control strategy for wind energy conversion systems in MPPT and stall regions," in 2013 IEEE Energy Conversion Congress and Exposition (ECCE), Sep. 2013, pp. 2412-2419.

[6] J. Chen, J. Chen, and C. Gong, "New Overall Power Control Strategy for Variable-Speed Fixed-Pitch Wind Turbines Within the Whole Wind Velocity Range," IEEE Transactions on Industrial Electronics, vol. 60, no. 7, pp. 2652-2660, Jul. 2013.

[7] C. Lumbreras, J. M. Guerrero, P. Garca, F. Briz, and D. D. Reigosa, "Control of a Small Wind Turbine in the High Wind Speed Region," IEEE Transactions on Power Electronics, vol. 31, no. 10, pp. 69806991, Oct. 2016.

[8] J. Bates and K. Grimshaw, "Simulation of massive inertia loads using feedback techniques," Proceedings of the Institution of Electrical Engineers, vol. 113, no. 3, pp. 509-516, Mar. 1966.
[9] A. Abo-Khalil, "A new wind turbine simulator using a squirrel-cage motor for wind power generation systems," in 2011 IEEE Ninth International Conference on Power Electronics and Drive Systems (PEDS), Dec. 2011, pp. 750-755.

[10] F. Farret, R. Gules, and J. Marian, "Micro-turbine simulator based on speed and torque of a DC motor to drive actually loaded generators," in , Proceedings of the 1995 First IEEE International Caracas Conference on Devices, Circuits and Systems, 1995, Dec. 1995, pp. 89-93.

[11] B. Rabelo, W. Hofmann, and M. Gluck, "Emulation of the static and dynamic behaviour of a wind-turbine with a DC-machine drive," in Power Electronics Specialists Conference, 2004. PESC 04. 2004 IEEE 35th Annual, vol. 3. IEEE, Jun. 2004, pp. 2107- 2112 Vol.3.

[12] H. Zha and Z. Zong, "Emulating Electric Vehicle's Mechanical Inertia Using an Electric Dynamometer," in 2010 International Conference on Measuring Technology and Mechatronics Automation (ICMTMA), vol. 2, Mar. 2010, pp. 100-103.

[13] S.-H. Song, B.-C. Jeong, H.-I. Lee, J.-J. Kim, J.-H. Oh, and G. Venkataramanan, "Emulation of output characteristics of rotor blades using a hardware-in-loop wind turbine simulator," in Twentieth Annual IEEE Applied Power Electronics Conference and Exposition, 2005. APEC 2005, vol. 3, Mar. 2005, pp. 1791-1796 Vol. 3.

[14] L. Weijie, Y. Minghui, Z. Rui, J. Minghe, and Z. Yun, "Investigating instability of the wind turbine simulator with the conventional inertia emulation scheme," in 2015 IEEE Energy Conversion Congress and Exposition (ECCE), Sep. 2015, pp. 983-989.

[15] J. Neely, S. Glover, J. Finn, F. White, B. Loop, and O. Wasynczuk, "Wind turbine emulation for intelligent microgrid development," in 2012 IEEE International Conference on Cyber Technology in Automation, Control, and Intelligent Systems (CYBER), May 2012, pp. 28-33.

[16] J. Guerrero, C. Lumbreras, D. Reigosa, P. Garcia, and F. Briz, "Control and emulation of small wind turbines using torque estimators," in 2015 IEEE Energy Conversion Congress and Exposition (ECCE), Sep. 2015, pp. 997-1004.

[17] V. T. Buyukdegirmenci and P. T. Krein, "Induction Machine Characterization for Short-Term or Momentary Stall Torque," IEEE Transactions on Industry Applications, vol. 51, no. 3, pp. 2237-2245, May 2015.

[18] J. M. Guerrero, D. Reigosa, C. Blanco, F. Briz, and C. Lumbreras, "Sensorless speed control of a small wind turbine using the rectifier voltage ripple," in 2016 IEEE Energy Conversion Congress and Exposition (ECCE), Sep. 2016, pp. 1-8.

[19] D. Reigosa, D. Fernandez, T. Tanimoto, T. Kato, and F. Briz, "Comparative Analysis of BEMF and Pulsating High-Frequency Current Injection Methods for PM Temperature Estimation in PMSMs," IEEE Transactions on Power Electronics, vol. 32, no. 5, pp. 3691-3699, May 2017.

[20] S. J. Underwood and I. Husain, "Online Parameter Estimation and Adaptive Control of Permanent-Magnet Synchronous Machines," IEEE Transactions on Industrial Electronics, vol. 57, no. 7, pp. 24352443, Jul. 2010.

[21] S. Ichikawa, M. Tomita, S. Doki, and S. Okuma, "Sensorless control of permanent-magnet synchronous motors using online parameter identification based on system identification theory," IEEE Transactions on Industrial Electronics, vol. 53, no. 2, pp. 363-372, Apr. 2006.

[22] S. Heier, Grid Integration of Wind Energy Conversion Systems, 2nd ed. Wiley, Jun. 2006. 